\title{
Microcomputer-based Discontinuous PWM for DC-link Current Harmonic Reduction in Three-phase VSIs
}

\author{
Koroku Nishizawa* Student Member, Jun-ichi Itoh ${ }^{* a)}$ Senior Member \\ Akihiro Odaka** Member, Akio Toba ${ }^{* *} \quad$ Senior Member \\ Hidetoshi Umida $^{* *}$ Fellow
}

(Manuscript received Jan. 7, 2019, revised June 10, 2019)

\begin{abstract}
This paper proposes a novel discontinuous pulse width modulation (DPWM) strategy to reduce the switchingfrequency-order DC-link current harmonics for a two-level three-phase voltage source inverter (VSI). The proposed modulation method realizes a long lifetime of the smoothing capacitor to the motor drive system. Furthermore, the proposed strategy requires only one carrier; thus, high cost hardware such as field-programmable gate arrays are unnecessary. The DC-link current harmonics are reduced by shifting two unclamped modulating signals in every half control period. In addition, the injection of the zero sequence signal to all discontinuous modulating signals optimizes the phase of the clamped modulating signal and its clamped value according to the conditions of the output phase currents; consequently, the DC-link current harmonics are reduced even when the load power factor varies. Experiments confirm that the proposed DPWM strategy can reduce the DC-link current harmonics by a maximum of $18.3 \%$ at a modulation index of 0.705 and a load power factor of 0.819 .
\end{abstract}

Keywords: two-level voltage source inverter, discontinuous PWM, DC-link capacitors, DC-link current harmonics

\section{Introduction}

Three-phase AC motors are widely utilized in widespread applications such as traction and automotive and so on ${ }^{(1)-(7)}$. Recently, lifetime extension of such system has been actively researched $^{(8)-(12)}$. Generally, electrolytic capacitors are applied in the DC-link of the PWM inverter as a smoothing capacitor. The smoothing capacitor acts as an energy buffer to stabilize the DC-link voltage and guarantees a dynamic performance of the system by suppressing an overshoot voltage during a transient state. These functions are realized by using bulky electrolytic capacitors which make the system large and less reliable.

The DC-link capacitors absorb large switching-frequency harmonics contained in the PWM inverter DC-link current, leading joule losses in the equivalent series resistance (ESR) of the capacitors. The internal heating considerably worsens the capacitor reliability according to the Arrhenius equation $^{(13)}$. There are several methods to extend the lifetime of the smoothing capacitor. One of the approaches is the application of film capacitors instead of the electrolytic capacitor as the smoothing capacitor ${ }^{(14)}$. However, this method makes the system larger due to its low energy density.

Meanwhile, it is also possible to extend the lifetime of the

a) Correspondence to: Jun-ichi Itoh. E-mail: itoh@ vos.nagaokaut. ac.jp

* Nagaoka University of Technology

1603-1, Kamitomioka-machi, Nagaoka, Niigata 940-2188, Japan

${ }^{* *}$ Fuji Electric Co., Ltd.

1, Fuji-machi, Hino, Tokyo 191-8502, Japan smoothing capacitor by reducing the DC-link current harmonics of VSI. So far, numerous modulation methods of VSI, which reduce the DC-link current harmonics of VSI, have been also proposed ${ }^{(8)-(10)(15)}$. In (8)-(10), double carriers, two inverted triangular carriers, are used as a double-carriercomparison pulse width modulation (PWM). In these modulation methods, the DC-link current harmonics are reduced by comparing only one certain phase modulating signal with the inverse triangular carrier and comparing the other two modulating signals with the original triangular carrier. However, this method leads to a constraint of the digital hardware due to the generation of the inverse triangular carrier. Furthermore, when the load power factor becomes lower than 0.866 , the DC-link current harmonics cannot be reduced by these methods.

As another approach to minimize the DC-link current harmonics, a new space vector PWM (SVPWM) has been proposed $^{(15)}$. In this SVPWM, the optimized voltage space vectors for the DC-link current harmonic reduction are selected on the basis of the detected output phase current directions to adapt to the variation of the load power factor. However, the employment of this SVPWM also leads a constraint of the digital hardware such as FPGA because the SVPWM not only compares the on-duties of the selected output voltage space vectors with single carrier but also decides the gating signals based on the carrier comparison results to realize the optimized combinations of the voltage space vectors.

This paper proposes a novel carrier-comparison DPWM which uses only one carrier to reduce the switchingfrequency-order DC-link current harmonics of VSI and eliminates the need of the complex digital hardware. In other 
words, the proposed DPWM is simply implemented with the general-purpose microcomputer without additional digital hardware. In order to reduce the DC-link current harmonics by using just only one carrier, two unclamped phase modulating signals of the conventional DPWM are optimally shifted in every half control period. Furthermore, the injection of the zero sequence signal to all discontinuous modulating signals optimizes the phase of clamped modulating signal and its clamped value according to the conditions of the output phase currents; consequently, the DC-link current harmonics are reduced even when the load power factor varies.

This paper is organized as follows; first, the reduction method of the DC-link current harmonics by using the novel modulating signals of the DPWM is introduced. Next, the mechanism to adapt the variation of the load power factor is explained. Then, the performances on the input current harmonics, the output current harmonics and the inverter efficiency are compared between the conventional and proposed DPWM by analysis and experiment. Finally, the electrolytic capacitor lifetimes with those DPWM are estimated and compared.

\section{Proposed PWM Method to Reduce DC-link Current Harmonics of VSIs}

2.1 Conventional Discontinuous PWM Figure 1 shows a three-phase two-level VSI with a motor load. This circuit consists of three legs. If IGBTs are treated as ideal switches, the conduction status of any one leg can be represented by binary switching functions:

$$
s_{x}=\left\{\begin{array}{ll}
1, & \left(\mathrm{~S}_{x p}: \mathrm{ON}, \mathrm{S}_{x n}: \mathrm{OFF}\right) \\
0, & \left(\mathrm{~S}_{x p}: \mathrm{OFF}, \mathrm{S}_{x n}: \mathrm{ON}\right)
\end{array}, \quad(x=u, v, w) . \cdots\right.
$$

Figure 2 shows the modulating signals of the continuous PWM (CPWM), conventional DPWM and its injected zero sequence signal at the modulation index of 0.8 . The discontinuous modulating signals are obtained by injecting the zero sequence signal $v^{*}$ offset into the continuous modulating signals as ${ }^{(16)}$ :

$$
\begin{aligned}
& \left\{\begin{array}{l}
v_{u . C P W M}^{*}=m \cdot \cos (2 \pi f t) \\
v_{v \cdot C P W M}^{*}=m \cdot \cos (2 \pi f t-2 \pi / 3), \\
v_{w . C P W M}^{*}=m \cdot \cos (2 \pi f t+2 \pi / 3)
\end{array}\right. \\
& v_{\text {offset }}^{*}=\left\{\begin{array}{cl}
1-\left|v_{\max }\right| & \text { if }\left|v_{\max }\right| \geq\left|v_{\min }\right| \\
-1+\left|v_{\min }\right| & \text { if }\left|v_{\min }\right|<\left|v_{\max }\right|
\end{array}\right. \\
& \text { and }\left\{\begin{array}{l}
v_{\max }=\max \left[v_{u . C P W M}^{*}, v_{v . C P W M}^{*}, v_{w . C P W M}^{*}\right] \\
v_{\min }=\min \left[v_{u . C P W M}^{*}, v_{v \cdot C P W M}^{*}, v_{w . C P W M}^{*}\right]
\end{array}\right. \\
& \text {................ (3) } \\
& v_{x . D P W M}^{*}=v_{x . C P W M}^{*}+v_{o f f s e t}^{*}, \quad(x=u, v, w),
\end{aligned}
$$

where $m$ is the modulation index.

Figure 3 shows the zoomed-in waveforms of the modulating signals of the conventional DPWM, the three-phase switching functions and the DC-link current at the modulation index of 0.8 , the phase angle of 50 degrees and the unity load power factor. The instantaneous value of the DC-link current is a superposition summation of the switched current pulses from each phase leg and calculated as ${ }^{(17)}$ :

$$
i_{D C . i n}=\sum_{x=u, v, w}\left(s_{x} \times i_{x}\right) .
$$

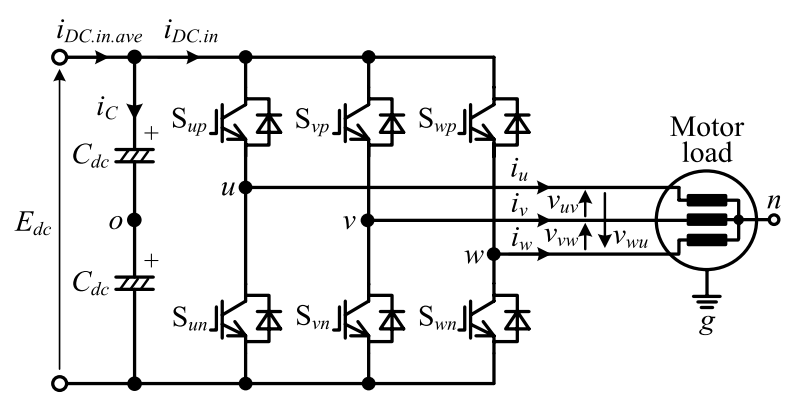

Fig. 1. Three-phase two-level VSI with motor load

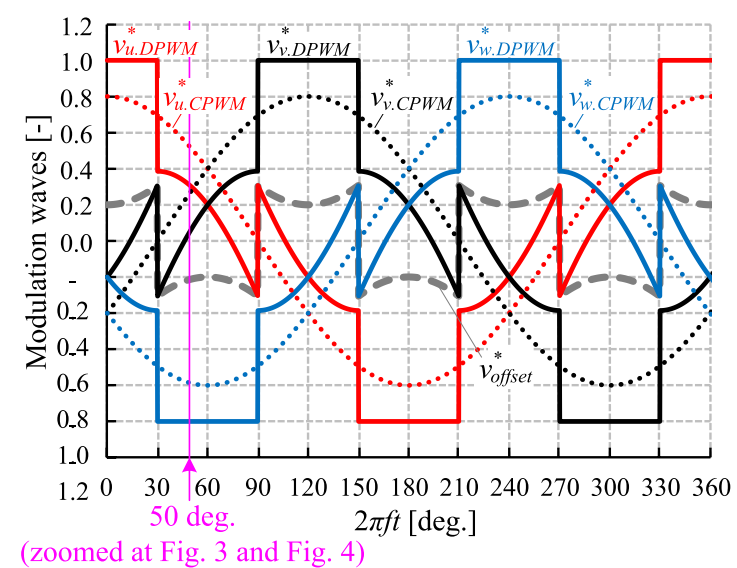

Fig. 2. Modulating signals of CPWM, conventional DPWM and its injected zero sequence signal at $m=0.8$

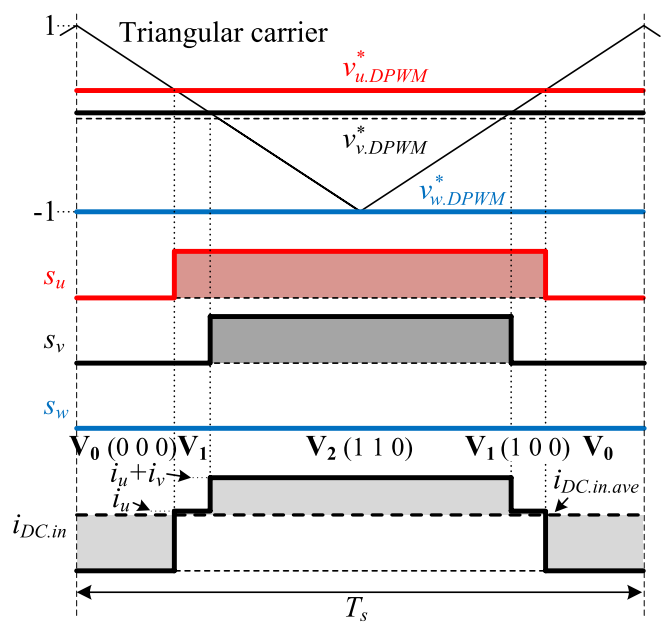

Fig. 3. Zoomed-in waveforms of modulating signals of conventional DPWM, switching functions and DC-link current at $m=0.8,2 \pi f t=50$ deg., $\cos \varphi=1$

The shaded areas in the DC-link current waveform indicates the time integral of the difference between the instantaneous value and an average value of the DC-link current. These area correspond to the root-mean-square (RMS) value of the DClink capacitor current based on the geometrical difference between the RMS value of the DC-link current $i_{D C \text {.in.RMS }}$ and the average value of the DC-link current $i_{D C \text {.in.ave }}$ as follows:

$$
\begin{aligned}
& i_{C . R M S}\left(T_{s}\right)=\sqrt{i_{D C . i n . R M S}^{2}\left(T_{s}\right)-i_{D C . i n . a v e}^{2}} \\
& \text { and }\left\{\begin{array}{l}
i_{D C . i n . R M S}\left(T_{s}\right)=\sqrt{\frac{1}{T_{s}} \int_{0}^{T_{s}} i_{D C . i n}^{2} d t}, \ldots \ldots \\
i_{D C . i n . a v e}=\frac{3}{4} m \cdot I_{m} \cos \varphi
\end{array}\right.
\end{aligned}
$$




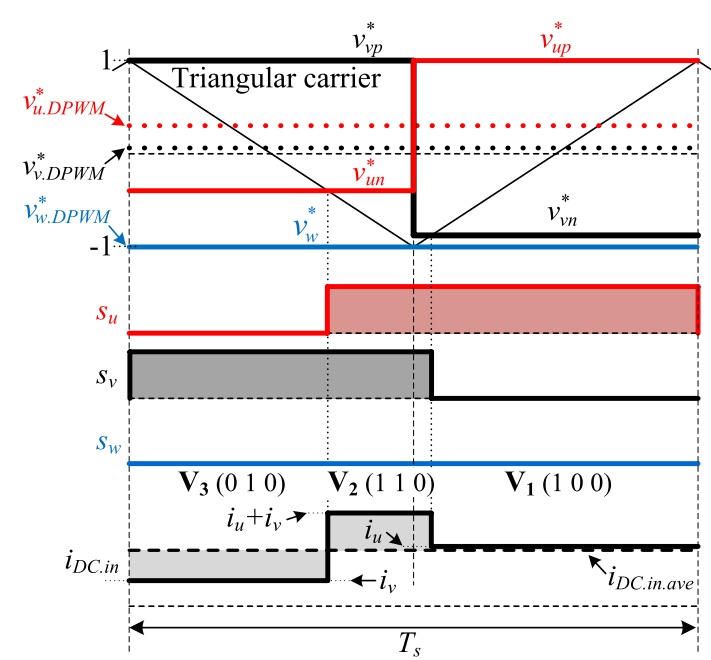

Fig. 4. Zoomed-in waveforms of modulating signals of proposed DPWM, switching functions and DC-link current at $m=0.8,2 \pi f t=50$ deg., $\cos \varphi=1$

where $T_{s}$ is the control period, $I_{m}$ is the maximum value of the output phase current and $\varphi$ is the load power factor angle. Note that a smaller fluctuation of the DC-link current around its average value results in a smaller RMS value of the DC-link capacitor current ${ }^{(18)}$. In cases where the conventional DPWM is applied, the center of the gate pulses are matched to the center of the control period, leading a long overlap period of the gate pulses. This results in a large fluctuation of the DC-link current around its average value, i.e. the high DC-link capacitor current harmonics.

2.2 Microcomputer-based Approach to Reduce Harmonics Figure 4 shows the zoomed-in waveforms of the modulating signals of the proposed DPWM, the three-phase switching functions and the DC-link current at the modulation index of 0.8 , the phase angle of 50 degrees and the unity load power factor. The operation of the proposed DPWM changes corresponding to the load power factor. In this section, the load power factor is considered as unity. The basic concept of the proposed DPWM for the DC-link current harmonic reduction is to shorten the zero-vector period, i.e. period where $\left(\begin{array}{lll}s_{u} & s_{v} & s_{w}\end{array}\right)=\left(\begin{array}{lll}0 & 0 & 0\end{array}\right)$ or $\left(\begin{array}{lll}1 & 1 & 1\end{array}\right)$, during the control period, leading to the reduction of the DC-link current fluctuation around its average value. Therefore, the basic concept of the proposed DPWM is similar to that of the conventional DC-link current harmonic reduction SVPWM method $^{(15)}$. In the proposed DPWM, this concept is realized under the premise that the modulating signals can be updated at positive and negative peaks of the triangular carrier, which is constraint of the microcomputer. In order to adjust the gate pulse positions as shown in Fig. 4, only two unclamped phase modulating signals $v^{*}{ }_{u . D P W M}$ and $v^{*}{ }_{v . D P W M}$ should be updated, whereas the clamped modulating signal $v^{*}{ }_{w . D P W M}$ does not change. Each proposed modulating signal is generated by shifting the unclamped original DPWM modulating signal as:

$$
\begin{aligned}
& \left\{\begin{array}{l}
v_{x p}^{*}=1 \\
v_{x n}^{*}=2 \cdot v_{x . D P W M}^{*}-1
\end{array} \quad\left(\text { if } v_{x . D P W M}^{*} \geq 0\right)\right. \\
& \left\{\begin{array}{l}
v_{x p}^{*}=2 \cdot v_{x . D P W M}^{*}+1 \\
v_{x n}^{*}=-1
\end{array} \quad\left(\text { if } v_{x . D P W M}^{*}<0\right),\right.
\end{aligned}
$$

Table 1. Sector definitions of proposed DPWM

\begin{tabular}{c|ccc|cc}
\hline \hline \multirow{2}{*}{ Sector } & \multicolumn{2}{|c|}{ Current polarity } & \multicolumn{2}{|c}{ Optimized clamped value } \\
& \multicolumn{2}{|c|}{ Positive, N: Negative) } & \multicolumn{2}{c}{$K_{O C V}$} \\
\hline$i_{u}$ & $i_{v}$ & $i_{w}$ & Driving & Reg. Braking \\
\hline $\mathrm{A}$ & $\mathrm{P}$ & $\mathrm{N}$ & $\mathrm{N}$ & 1 & -1 \\
$\mathrm{~B}$ & $\mathrm{P}$ & $\mathrm{P}$ & $\mathrm{N}$ & -1 & 1 \\
$\mathrm{C}$ & $\mathrm{N}$ & $\mathrm{P}$ & $\mathrm{N}$ & 1 & -1 \\
$\mathrm{D}$ & $\mathrm{N}$ & $\mathrm{P}$ & $\mathrm{P}$ & -1 & 1 \\
$\mathrm{E}$ & $\mathrm{N}$ & $\mathrm{N}$ & $\mathrm{P}$ & 1 & -1 \\
$\mathrm{~F}$ & $\mathrm{P}$ & $\mathrm{N}$ & $\mathrm{P}$ & -1 & 1 \\
\hline \hline
\end{tabular}

where $v_{x p}^{*}$ is the positively-shifted modulating signal, and $v^{*}{ }_{x n}$ is the negatively-shifted modulating signal. Note that the overlap period between two unclamped phases' switching functions, $s_{u}$ and $s_{v}$ in Fig. 4 , should be shortened to reduce the fluctuation of the DC-link current around its average value. Therefore, these two phase modulating signals are alternately shifted to the positive side. Besides, the averaged values of the shifted modulating signals in each control period are same as those of the original signals, whereas the pulse widths of the switching functions are unchanged ${ }^{(19)}$.

However, note that the reduction effect on the DC-link current harmonics by the use of the shifted modulation signals is dependent on the load power factor because the instantaneous value of the DC-link current is also dependent on the output phase currents. Thus, it is necessary to deal with the wide variation of the load power factor, which is a typical requirement of the motor drive system.

\subsection{Adaption to Wide Load Power Factor Range}

Table 1 lists the sector definition of the load current conditions. These sectors are determined by the combination of the detected output phase current directions.

Figure 5 shows the conventional and proposed discontinuous modulating signals at the modulation index of 0.8 and the load power factor of 0.966 (15 deg. lagging). In order to reduce the DC-link current harmonics at any condition of the load power factor, first, three conventional discontinuous modulating signals $v^{*}{ }_{x . D P W M}(x=u, v, w)$ are added with the offset $v^{*}$ offset.2 to obtain the voltage reference with the offset $v^{*}{ }^{*} P D P W M$ as:

$$
\begin{aligned}
& v_{x . P D P W M}^{*}=v_{x . D P W M}^{*}+v_{\text {offset. } 2}^{*} \\
& \text { and } v_{\text {offset } .2}^{*}= \begin{cases}K_{O C V}-v_{u . D P W M}^{*} & \text { if sector }=\mathrm{A}, \mathrm{D} \\
K_{O C V}-v_{v . D P W M}^{*} & \text { if sector }=\mathrm{B}, \mathrm{E} \\
K_{O C V}-v_{w . D P W M}^{*} & \text { if sector }=\mathrm{C}, \mathrm{F}\end{cases}
\end{aligned}
$$

where $K_{O C V}$ is the optimized clamped value of the modulating signal in each proposed sector listed in Table 1 . The offset value $v^{*}$ offset. 2 is optimized according to the conditions of the output phase currents and the clamped phase of the modulating signals. In the case of sector $\mathrm{B}$, for example, where $i_{u}$ and $i_{v}$ are positive and $i_{w}$ is negative, $w$-phase switching function $s_{w}$ must be zero to obtain the minimum fluctuation of the DC-link current around its average value. If $s_{w}$ becomes 1 during the sector $\mathrm{B}$, the instantaneous value of the DClink current becomes negative, which leads to a large fluctuation, i.e. the large increase in the DC-link current harmonics. Next, two unclamped offset-added modulating signals $v^{*}{ }_{x . P D P W M}$ are shifted based on the sub-section 2.2, resulting 


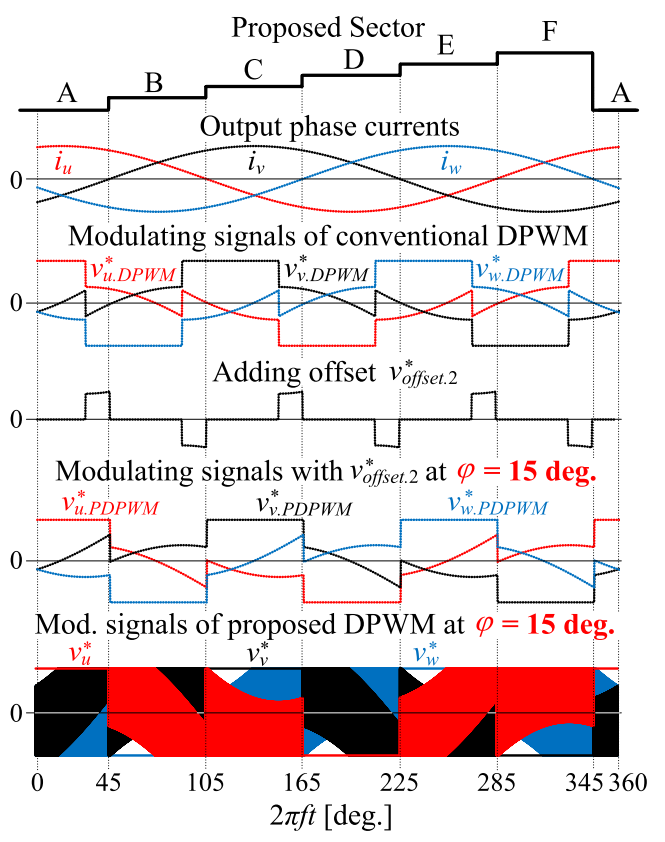

Fig. 5. Proposed modulating signals at $m=0.8, \cos \varphi=$ 0.966 (15 deg. lagging). $v^{*}{ }_{x . P D P W M}$ is generated by adding an offset $v^{*}{ }_{\text {offset. } 2}$ to $v^{*}{ }_{x . D P W M}$ to maintain the clamped period of the modulating signal at each proposed sector. The proposed modulating signals are then generated by shifting two unclamped modulating signals of $v^{*}{ }_{x . P D P W M}$ in every half control period

in the proposed modulating signals $v^{*}{ }_{x}$. With this optimization for the clamped phase and its value of the modulating signal based on the load current conditions, the DC-link current harmonics is reduced even when the load power factor varies $^{(19)}$.

In case of the regenerative braking mode, the average value of the DC-link current become a negative value. Therefore, the optimized clamped value $K_{O C V}$ of the modulating signal for the reduction of the DC-link current fluctuation around its average value in each proposed sector is reversed between driving and regenerative braking modes as listed in Table 1. Note that whether the motor operating mode is driving or regenerative braking can be detected from the polarity combinations of the modulating signals and the detected output phase currents ${ }^{(15)}$. In addition, the shifting of the other two unclamped offset-added modulating signals in every half control period is also performed in the case of regenerative braking mode as the driving mode.

Figure 6 shows the conventional and proposed discontinuous modulating signals at the modulation index of 0.8 and the load power factor of 0.707 ( $45 \mathrm{deg}$. lagging). In the case where the load power factor is lower than 0.866 $(\varphi<30$ deg.), the proposed offset-added modulating signals $v^{*}{ }_{x . P D P W M}$ might be more than 1 or lower than -1 due to the addition of the offset $v_{\text {offset. } 2}^{*}$ in each sector, leading an overmodulation operation. Therefore, the conventional DPWM is applied in these periods as shown in the gray-colored periods in Fig. 6. Accordingly, the phase of the clamped modulating signal is not optimized for the reduction of the DC-link current harmonics; thus, the modulating signal shift in every half control period are not performed in these periods.

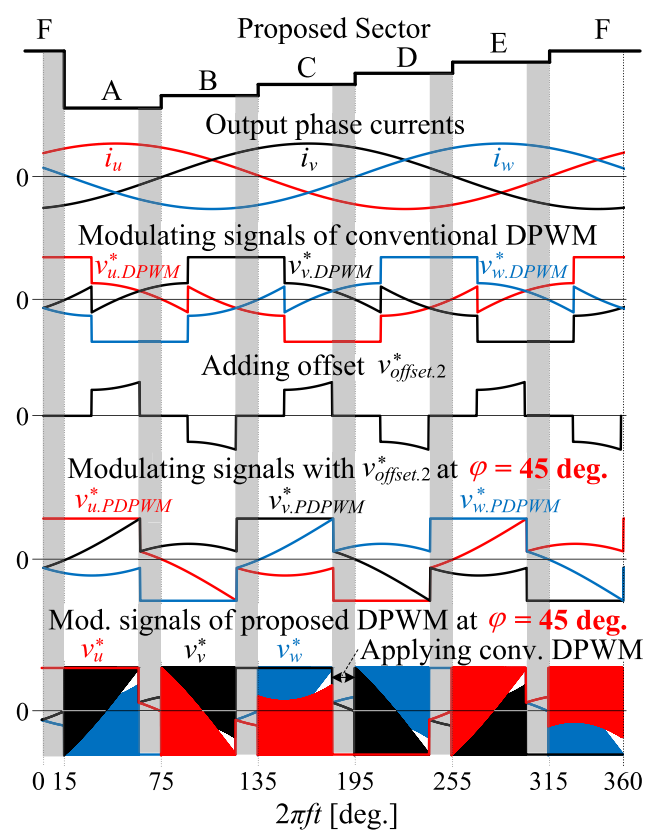

Fig. 6. Proposed modulating signals at $m=0.8, \cos \varphi$ $=0.707$ (45 deg. lagging). In gray-colored periods, the conventional DPWM are applied to avoid the overmodulation operation due to the addition of $v^{*}$ offset.2

\section{Analytical Evaluations}

3.1 DC-link Capacitor RMS Current As explained in the sub-section 2.1, the RMS value of the DC-link capacitor current is dependent on $m, \varphi$ and the switching patterns. The DC side of the three-phase VSI operates at sixfold fundamental frequency; hence, the normalized DC-link capacitor RMS current can be calculated based on (6) by considering only a sixth of the fundamental period:

$I_{C . R M S \text { (p.u.) }}=\frac{1}{I_{m}} \sqrt{\frac{3}{\pi} \int_{0}^{\frac{\pi}{3}}\left(\sum\left[\frac{t_{x}}{T_{s}}\left(i_{D C . i n . x}-i_{D C . i n . a v e}\right)^{2}\right]\right) d \theta}$

where $t_{x}$ is the ON duty of a VSI voltage space vector $\mathbf{V}_{\mathbf{x}}$ $\left(s_{u}, s_{v}, s_{w}\right)$ within $T_{s}$, and $i_{D C . i n . x}$ is the instantaneous DC-link current value with this voltage space vector $\mathbf{V}_{\mathbf{x}}$.

Figure 7 shows the analytical results of the DC-link capacitor current with regard to the modulation index $m$ and the load power factor angle $\varphi$. It can be seen from Fig. 7 that the proposed DPWM performs better in terms of the DC-link capacitor RMS current compared to the conventional DPWM under any cases of $m$ and $\varphi$. The characteristic to reduce the harmonic components in the DC-link capacitor current is same between driving and regenerative braking modes. In addition, a higher load power factor absolute value $|\cos \varphi|$ leads to a greater reduction effect on the DC-link capacitor RMS current, because the application ratio of the proposed discontinuous modulating signals becomes higher as the $|\cos \varphi|$ is higher. The power factor variation range of the motor loads is dependent on the applications; e.g., the rated speed and rated torque conditions are mainly used in the fan or pump applications, whereas any speed and torque conditions are expected in the traction applications such as train and electric vehicle. Furthermore, the load power factor is also dependent on the 


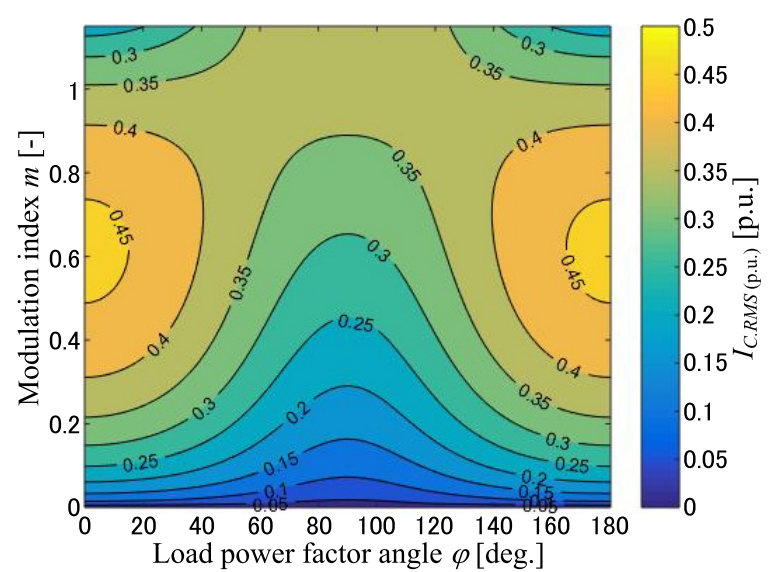

(a) Conventional DPWM.

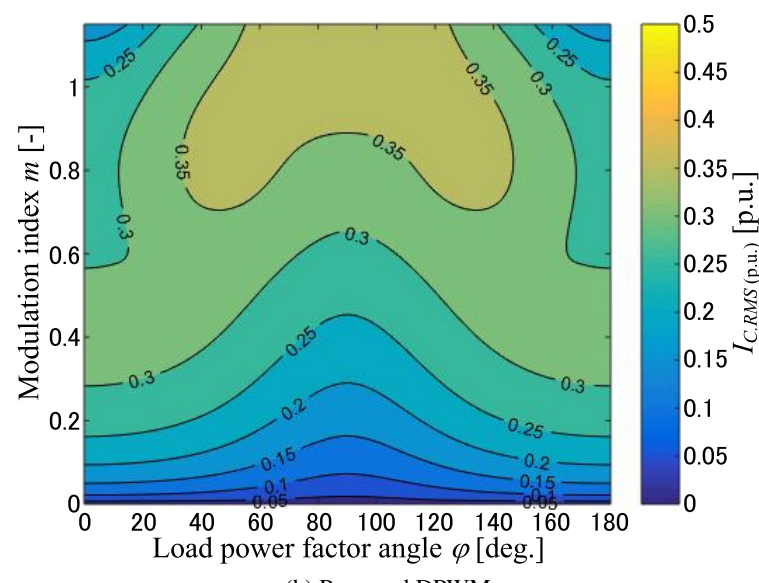

(b) Proposed DPWM.

Fig. 7. Analytical results of DC-link capacitor RMS current

motor type such as IM or PMSM. The actual effect on the DC-link capacitor RMS current reduction could be estimated by using this analytical results with the consideration of the expected operating conditions and their occurrence frequencies in each certain application.

3.2 Load Current Quality Since the switching frequency harmonics in the output voltage and output current of VSI have a critical role in the generation of the motor copper losses, the torque ripple of the test motor and the phase current total harmonic distortion (THD), the switching frequency harmonic characteristic of VSI is important to determine the performance of the modulation method. In this paper, the concept of the harmonic flux ${ }^{(20)}$ is used as an evaluation method for the load current quality characterized by the modulation method. This concept does not require the calculation of the harmonic spectrum of the inverter output voltage waveform, which is complicated for the proposed DPWM because of its gate pulse asymmetry in the carrier cycle. Assuming the switching frequency model of the load induction motor as an inductance $L$, a harmonic load current vector $\mathbf{I}_{\mathbf{h}}$ is proportional to a harmonic flux vector $\lambda_{\mathbf{h}}$, which is the time integral of the instantaneous error voltage vector,

$$
\lambda_{\mathbf{h}}=L \mathbf{I}_{\mathbf{h}}=\int_{N T_{s}}^{(N+1) T_{s}}\left(\mathbf{V}_{\mathbf{k}}-\mathbf{V}^{*}\right) d t=\int_{N T_{s}}^{(N+1) T_{s}} \mathbf{V}_{\mathbf{k h}} d t
$$

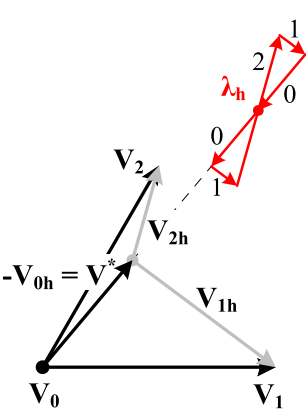

(a) Conventional DPWM

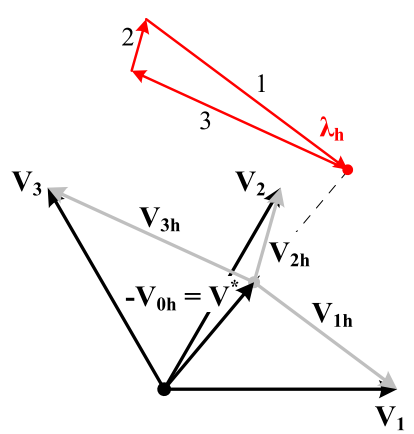

(b) Proposed DPWM.
Fig. 8. Harmonic flux trajectories at $m=0.8,2 \pi f t=$ 50 deg under same switching frequency

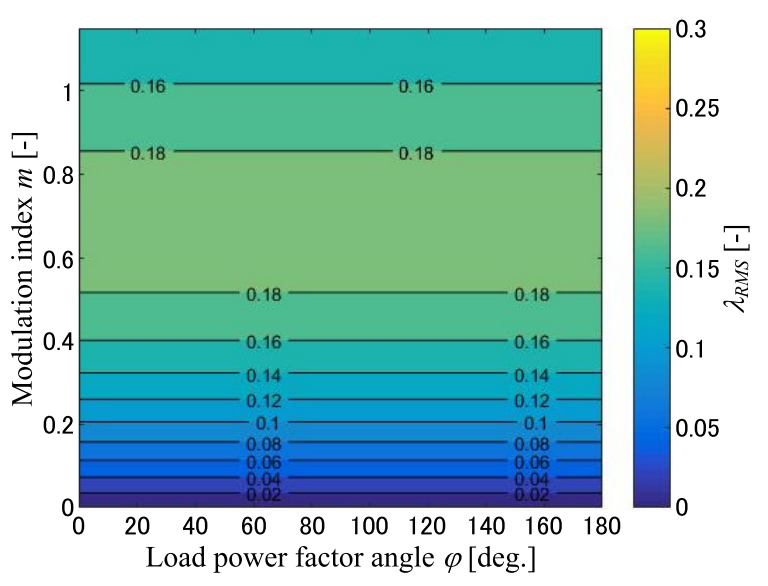

(a) Conventional DPWM.

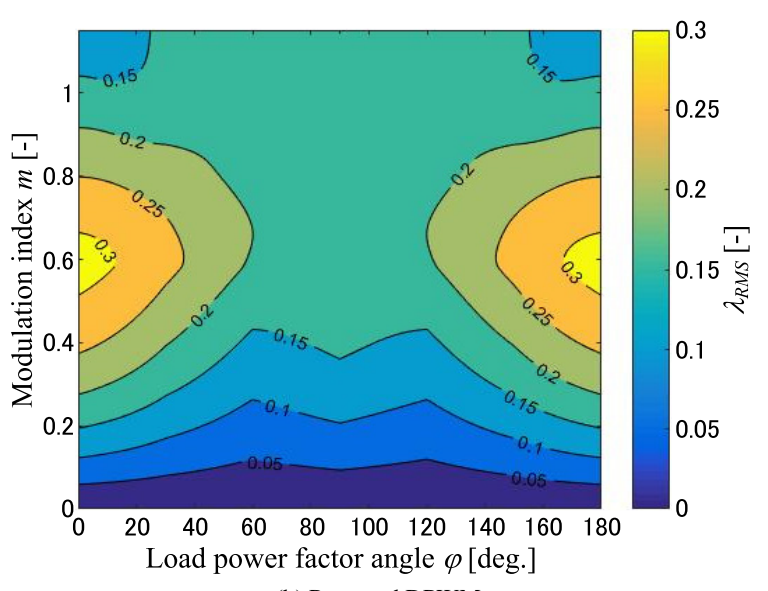

(b) Proposed DPWM.

Fig. 9. Comparison of harmonic flux RMS values

where $\mathbf{V}_{\mathbf{k}}(k=0 \sim 7)$ is the output voltage space vector of the 2-level VSI, $\mathbf{V}^{*}$ is the voltage reference vector, and $\mathbf{V}_{\mathbf{k h}}$ is the instantaneous error voltage vector.

Figure 8 shows the harmonic flux trajectories with the conventional and proposed DPWM at the modulation index of 0.8 , and the phase angle of $50 \mathrm{deg}$., under the same analytical conditions as in Figs. 3 and 4. The calculation of (10) and Fig. 8 visualize and evaluate the ripple current on a percarrier cycle base. Since the harmonic flux vector characteristic has six-fold space symmetry, the per-fundamental cycle (per 60 deg. in space) harmonic flux RMS value, which characterizes the load current quality and the harmonic losses in the test motor, is calculated as follows: 


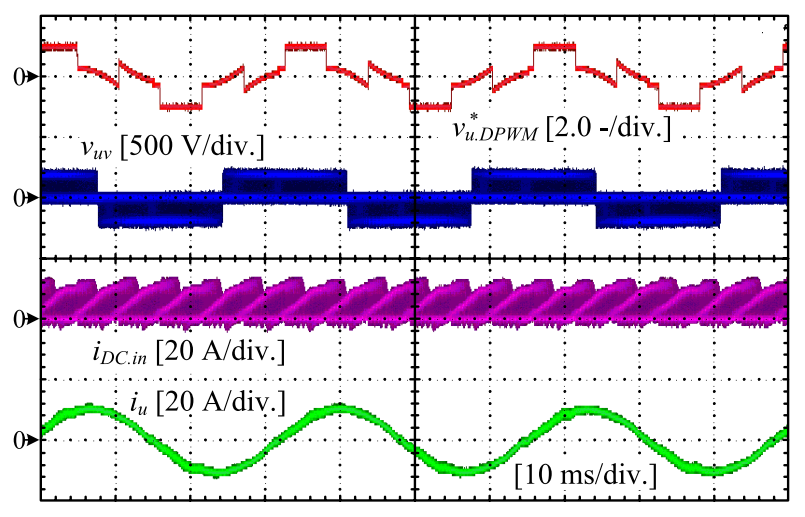

(a) Conventional DPWM.

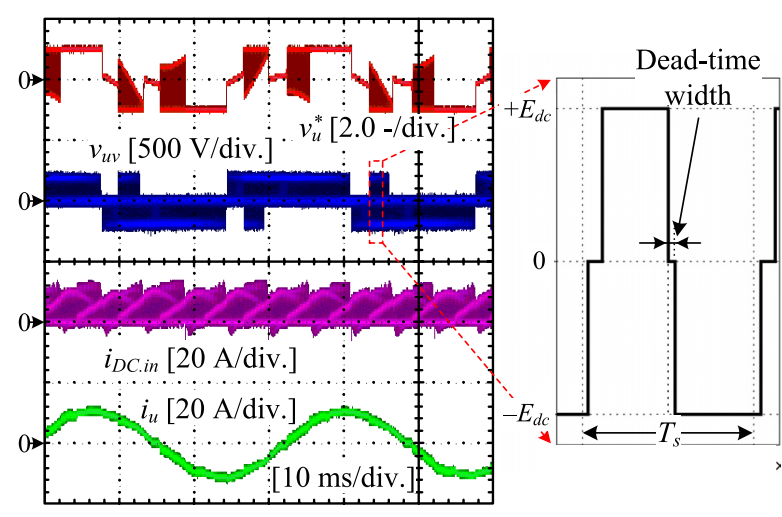

(b) Proposed DPWM

Fig. 10. Experimental waveforms at $m=0.705, \cos \varphi=0.819$ (35 deg. lagging), i.e. driving mode; $u$-phase modulating signal, output line-to-line voltage, DC-link current and output phase current. The zoomed-in waveform of $v_{u v}$ is from the simulation model using PLECS
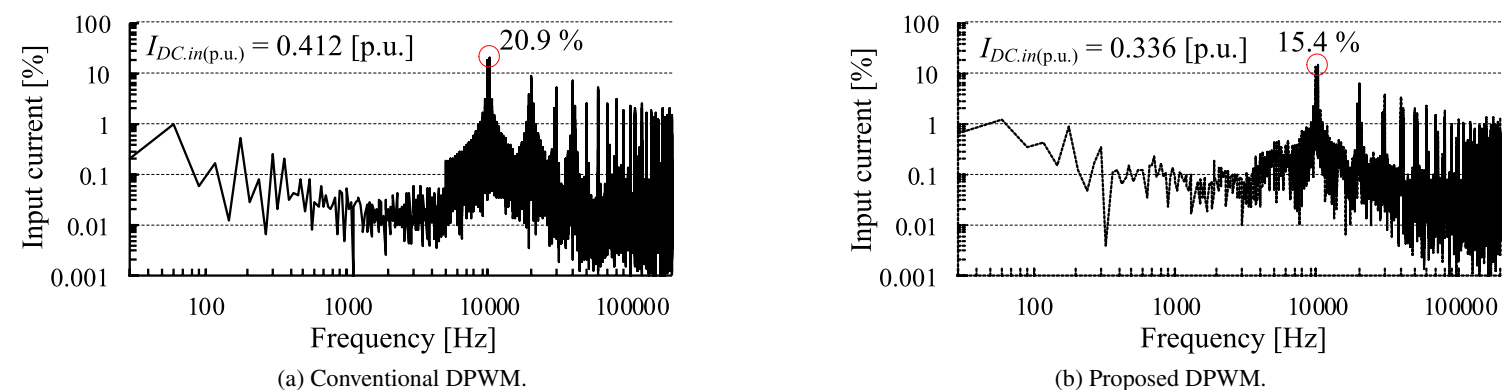

(b) Proposed DPWM.

Fig. 11. Harmonic components of DC-link current at $m=0.705, \cos \varphi=0.819$ (35 deg. lagging), i.e. driving mode (under same conditions as in Fig. 10)

$$
\lambda_{R M S}=\sqrt{\frac{3}{\pi} \int_{0}^{\frac{\pi}{3}} \int_{0}^{1}\left\|\lambda_{\mathbf{h}}\right\|^{2} d d . d \theta} .
$$

Figure 9 shows the analytical results of the harmonic flux RMS values with regard to the modulation index and the load power factor angle under the same switching frequency. In case of the conventional DPWM, the modulating signals are only dependent on the modulation index. Therefore, $\lambda_{R M S}$ obtained with the conventional DPWM is variable by only the modulation index. Nevertheless, in case of the proposed DPWM, the modulating signals are varied to reduce the DClink capacitor RMS current with regard to $m$ and $\varphi$. Furthermore, Figs. 8 and 9 confirm that the proposed DPWM leads to a larger $\lambda_{R M S}$ compared to the conventional DPWM. Note that the distance between the trajectories and the origin, initial value of $\lambda_{\mathbf{h}}$ at the beginning of the carrier cycle, is equal to the magnitude of the harmonic flux ${ }^{(20)}$. The proposed discontinuous modulating signals result in the application of the voltage space vector which is not the closest to $\mathbf{V}^{*}$, i.e. $\mathbf{V}_{\mathbf{3}}$ in Fig. 8. On the other hand, only voltage space vectors which are the closest to $\mathbf{V}^{*}$ are employed in the conventional DPWM. Therefore, the proposed DPWM leads to worse $\lambda_{R M S}$. Figure 9 also confirms that a higher $|\cos \varphi|$ leads to a larger $\lambda_{R M S}$, of which characteristics are opposite of the DC-link capacitor RMS current reduction effect shown in Fig. 7.

\section{Simulation and Experimental Results}

The performance of the proposed DPWM is verified experimentally. In this experiment, a three-phase induction motor
(MVK8115A-R, Fuji Electric Co. Ltd.) of which rated power is $3.7 \mathrm{~kW}$ is used as the test motor. The test motor is driven by the three-phase 2-level VSI, composed of IGBT power module (7MBP50RA120, Fuji Electric Co. Ltd.) and operated at the switching frequency of $10 \mathrm{kHz}$. The VSI is controlled by $\mathrm{V} / \mathrm{f}$ control with the conventional and proposed DPWM, which are implemented into an evaluation board (TMS320C6713, Texas Instruments). The load power factor is varied by controlling the torque reference of the load motor.

4.1 DC-link Current Harmonics Figure 10 shows the operating waveforms of VSI with the conventional and proposed DPWM at a modulation index of 0.705, and a load power factor of 0.819 (35 deg. lagging), i.e. driving mode. Under this load power factor condition, the application interval of the proposed DPWM is long; however, the conventional DPWM is also partially applied. Figure 10 confirms that the width of the step change in the DC-link current is reduced by an application of the proposed DPWM. On the other hand, the larger transitions between $+E_{d c}$ and $-E_{d c}$ seem to occur in the output line-to-line voltage with the proposed DPWM due to the application of the voltage space vector which is not the closest to $\mathbf{V}^{*}$. However, the zoomedin waveform of $v_{u v}$ shown in Fig. 10(b) confirms that the instantaneous voltage transition between $+E_{d c}$ and $-E_{d c}$ never occurs due to the dead-time period. Therefore, the proposed DPWM does not increase the motor surge voltage in practice compared to the conventional DPWM.

Figure 11 shows the harmonic components of the DC-link current under the same conditions as in Fig. 10. Note that 


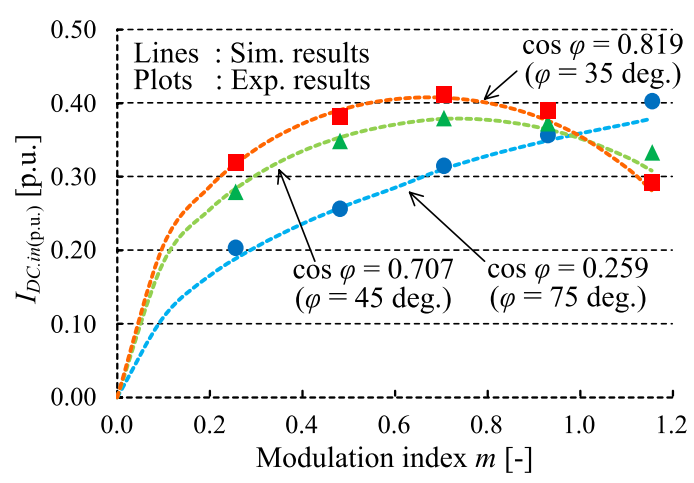

(a) Conventional DPWM.

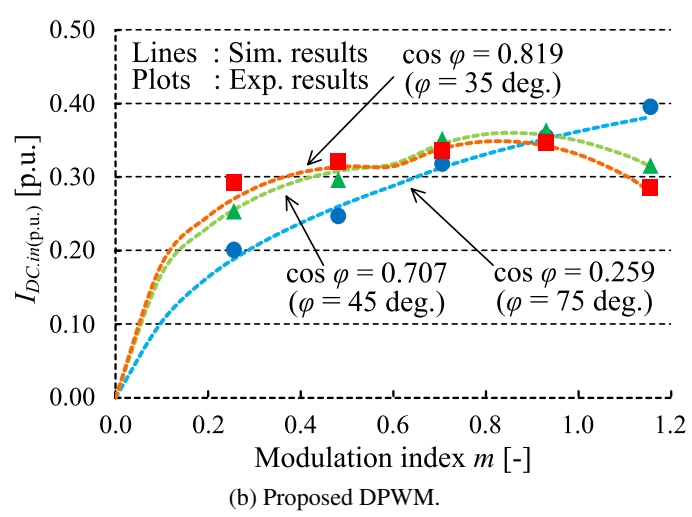

(b) Proposed DPWM

Fig. 12. Measured DC-link current harmonics in driving mode

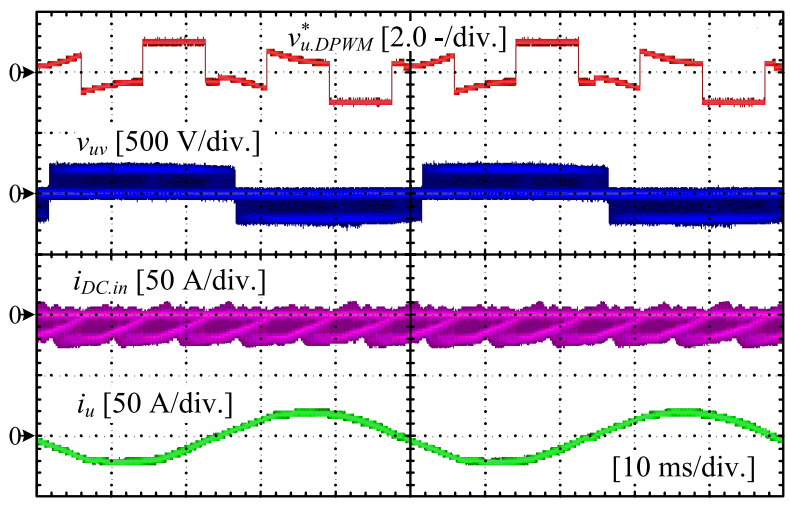

(a) Conventional DPWM

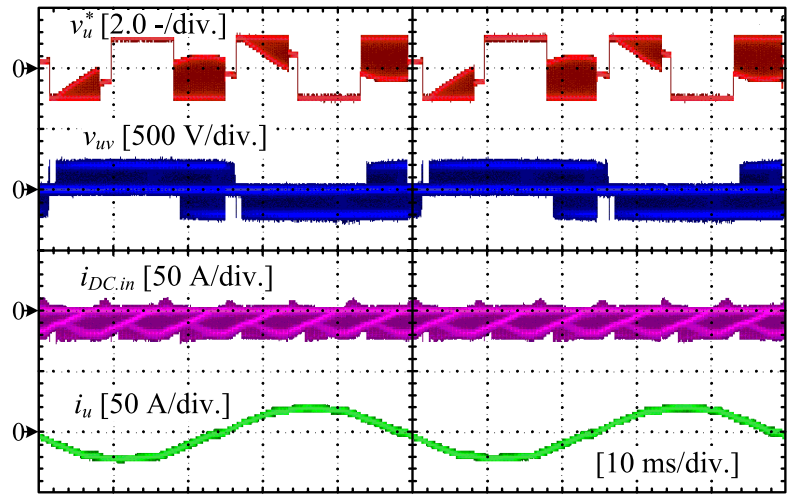

(b) Proposed DPWM.

Fig. 13. Experimental waveforms at $m=0.445, \cos \varphi=-0.766$ (140 deg. lagging), i.e. regenerative braking mode; $u$-phase modulating signal, output line-to-line voltage, DC-link current and output phase current

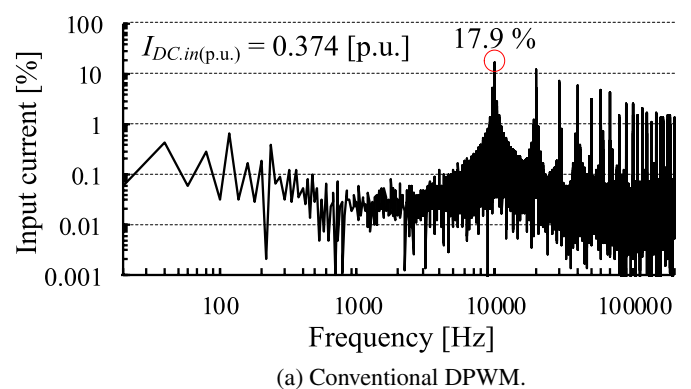

(a) Conventional DPWM.

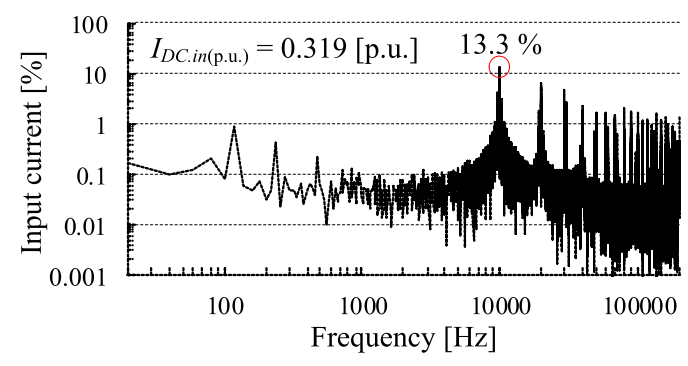

(b) Proposed DPWM

Fig. 14. Harmonic components of DC-link current at $m=0.445, \cos \varphi=-0.766$ ( 140 deg. lagging), i.e. regenerative braking mode (under same conditions as in Fig. 13)

$100 \%$ of the vertical axis indicates the maximum value of the output phase current. The application of the proposed DPWM reduces the switching frequency component of the DC-link current by 5.49 points.

Figure 12 shows the measured DC-link current harmonics with regard to the modulation index and load power factor in driving mode. The DC-link current harmonics is evaluated as the RMS value of the DC-link current, which is normalized by the maximum value of the output phase current as:

$$
I_{D C . \text {. } n \text { (p.u. })}=\frac{1}{I_{m}} \sqrt{\sum_{n=1}\left(i_{D C . i n . R M S . n}\right)^{2}} \ldots
$$

where $n$ is the harmonic order and $i_{D C . i n . R M S . n}$ is the RMS value of the $n$-order DC-link current harmonics component. The harmonic components of the DC-link current up to $20^{\text {th }}$ order of the switching frequency are considered in this evaluation. Figure 12 confirms that the DC-link current harmonics is reduced under any modulation index and load power factor conditions. In addition, it is also confirmed that higher load power factor leads to a greater DC-link current harmonicsreduction effect with the proposed DPWM.

Figure 13 shows the operating waveforms of VSI at the modulation index of 0.445 , and the load power factor of -0.766 (140 deg. lagging), i.e. regenerative braking mode. Even in regenerative braking mode, the width of the step change in the DC-link current can be reduced by the proposed DPWM, resulting in a reduced DC-link current harmonics.

Figure 14 shows the harmonic components of the DClink current under the same conditions as in Fig. 13. When the conventional DPWM is applied, the switching frequency component is $17.9 \%$ and the DC-link current harmonics is 0.374 p.u. The application of the proposed DPWM reduces the switching frequency component by 4.6 points, and the DC-link current harmonics by 0.319 p.u. The experimental 
results in Figs. 10-14 confirm that the proposed DPWM is effective to reduce the DC-link current harmonics for the motor drive system, of which the variation of the load power factor is considerably wide.

4.2 Output Phase Current Harmonics Figure 15 shows THD of the output $u$-phase current at the load power factor of 0.866 . Up to $40^{\text {th }}$-order harmonic components of the phase current are considered in this evaluation. Even though the analytic criterion of $\lambda_{R M S}$, explained in sub-section 3.2, and current THD are different, both of them are used to evaluate the output current quality. Figure 15 confirms the analytical results shown in Fig. 9 except for the high-modulation index area; in other words, the measured THD of the output phase current obtained with the proposed DPWM is higher than those obtained with the conventional DPWM. One of the reasons for the increase of the current THD with the proposed DPWM is the current detection error around zero-currentcrossing points. These errors cause the incorrect selection

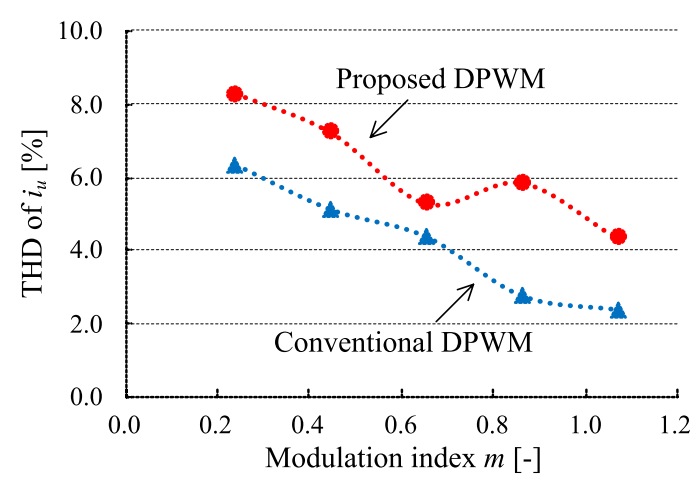

Fig. 15. THD of output $u$-phase current $i_{u}$ at $\cos \varphi=$ 0.866

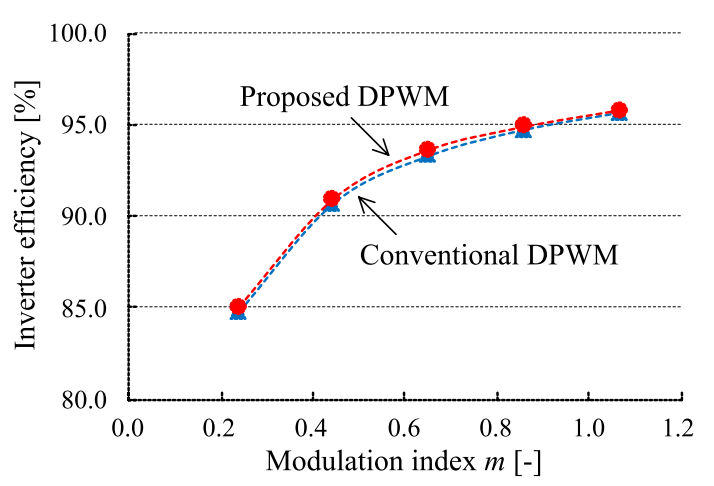

Fig. 16. Inverter efficiency comparison between conventional DPWM and proposed DPWM at $\cos \varphi=0.866$

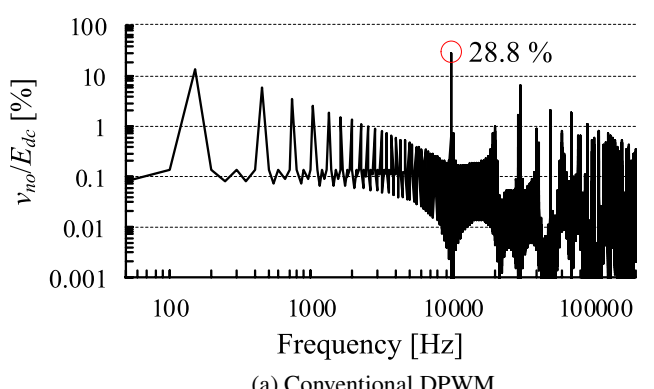

of the current sector (A-F), listed in Table 1, and increase the output phase current distortion, especially around the output phase current zero-crossing. This worse output phase current distortion might cause an increase of the iron loss in the load motor.

4.3 Inverter Efficiency Figure 16 shows the inverter efficiency comparison between the conventional and proposed DPWM at the load power factor of 0.866. The inverter efficiency is measured using Yokogawa WT1800 power analyzer. The application of the proposed DPWM slightly improves the inverter efficiency. In terms of the number of switching transitions, those number are same between the conventional and proposed DPWM, which can be observed from Figs. 3-4. In addition, the proposed DPWM always clamps the phase whose flowed current's absolute value is the maximum among three-phase currents due to the adaption process to the load power factor range, which can be observed from Fig. 5. In other words, the proposed DPWM enables to avoid the larger current chopping, leading to the smaller switching loss compared to those with the conventional DPWM under conditions where the load power factor is not unity.

4.4 Common-mode Voltage Figures 17-18 show the simulation results for VSI operating waveforms and the harmonic components of the common-mode voltage at the modulation index of 0.705 and the load power factor of 0.819 (under the same conditions as in experimental conditions in Figs. 10-11). The common-mode voltage $\left(v_{n o}\right)$ is defined as

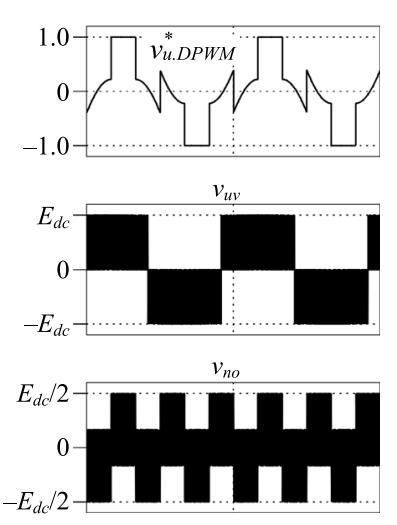

(a) Conventional DPWM.
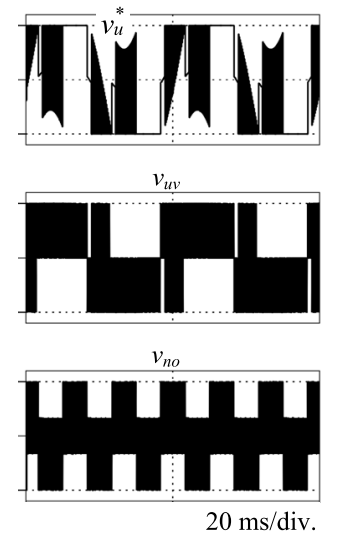

(b) Proposed DPWM
Fig. 17. Simulation results of common-mode voltage at $m=0.705, \cos \varphi=0.819$ under same conditions as in Figs. 10-11. This waveforms are from simulation model using PLECS

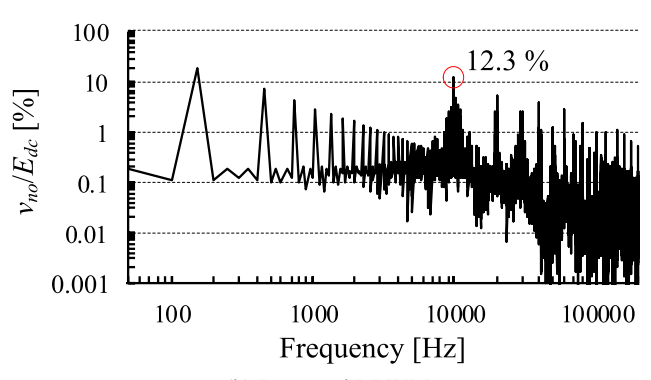

(b) Proposed DPWM.

Fig. 18. Harmonic components of common-mode voltage at $m=0.705, \cos \varphi=0.819$ (under same conditions as in Figs. 10-11, 17) 
the potential difference between the star point of the motor load $(n)$ and the center of the dc-bus $(o)$, which can be calculated as following.

$$
v_{n o}=\frac{v_{u o}+v_{v o}+v_{w o}}{3} .
$$

According to (13), the biggest $v_{n o}$ transition occurs when the both switching states of the zero vector $\left(\mathbf{V}_{\mathbf{0}}\left(\begin{array}{lll}0 & 0 & 0\end{array}\right)\right.$ and $\mathbf{V}_{\mathbf{7}}$ (l $\left.1 \begin{array}{ll}1 & 1\end{array}\right)$ ) are applied during control period. However, the proposed DPWM uses only one zero vector at a maximum during control period, which is the same as the conventional DPWM. Therefore, the proposed DPWM does not increase the $v_{n o}$ transition width. Spectrum of $v_{n o}$ shown in Fig. 18 confirm that the proposed DPWM reduces the switching frequency component by 16.5 points; however, increases the high-frequency components (higher than $100 \mathrm{kHz}$ ) compared to the conventional DPWM. This worse high-frequency $v_{n o}$ component might result in high common-mode current (motor leakage current). This may lead to the motor bearing failures, EMI noise and so on ${ }^{(21)(22)}$.

\section{Electrolytic Capacitor Lifetime Comparison}

Expected lifetime of the electrolytic capacitor is calculated as the multiplication of the specified lifetime $L_{o}$ in the manufacturer datasheet by three acceleration rates which are dependent on the ambient temperature $F_{T}$, the ripple current $F_{I}$, and the applied voltage $F_{V}{ }^{(13)}$. In this section, only the acceleration rate related to the ripple current $F_{I}$ is considered, and the other two factors $F_{T}$ and $F_{V}$ are assumed as 1 .

Table 2 lists the frequency coefficient $K_{f}$ of the rated ripple current flowing through the electrolytic capacitor (RWF series, Nippon Chemi-Con Corp. ${ }^{(23)}$ ), which has been used in the laboratory setup. With the consideration for the frequency dependency of the ESR in the electrolytic capacitors, the DC-link current harmonics is recalculated for its lifetime estimation as:

$$
I_{D C . i n . \text { freq }(\text { p.u. })}=\frac{1}{I_{m}} \sqrt{\sum_{n=1}\left(\frac{i_{D C . i n . R M S . n}}{K_{f}}\right)^{2}} \ldots \ldots \ldots
$$

Figure 19 shows the harmonic components of the DC-link current at the modulation index of 0.705 , and the load power factor of 0.819 (under the same conditions as in Figs. 1011) with the consideration for the frequency dependency of the ESR in the electrolytic capacitors. The application of the proposed DPWM reduces $I_{D C \text {.in.freq (p.u.) }}$ by $18.3 \%$ even when the frequency dependency of ESR in the electrolytic capacitor is considered. Note that it is necessary to consider the expected operation range for exact estimation of the capacitor lifetime. However, the actual operation range in motor speed and torque plane is dependent on each applications; therefore, full consideration with those is difficult. Therefore, simplified estimation is provided in this section with the assumption that this operating conditions (at modulation index of around 0.7 and load power factor of around 0.8) are the medium-speed and medium-torque conditions in the variable-speed drive systems, which are the frequent operating conditions. Assuming that the electrolytic capacitors in the VSI, modulated by the conventional DPWM, is designed at the worst case of the rated ripple current as $F_{I}=1$, the estimated lifetime $L_{n}$ of the electrolytic capacitor can be given
Table 2. Frequency coefficient of rated ripple current flowing through electrolytic capacitors (RWF series, Nippon Chemi-Con Corp.)

\begin{tabular}{c|ccccc}
\hline \hline Frequency [Hz] & 50 & 120 & 300 & $1 \mathrm{k}$ & $3 \mathrm{k} \sim$ \\
\hline Coefficient $K_{f}$ & 0.80 & 1.0 & 1.1 & 1.3 & 1.4 \\
\hline \hline
\end{tabular}

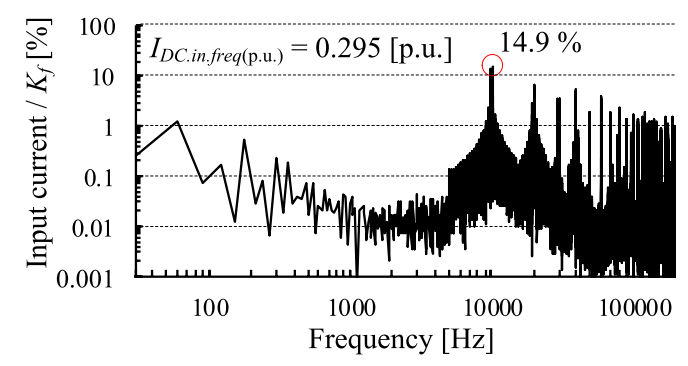

(a) Conventional DPWM.

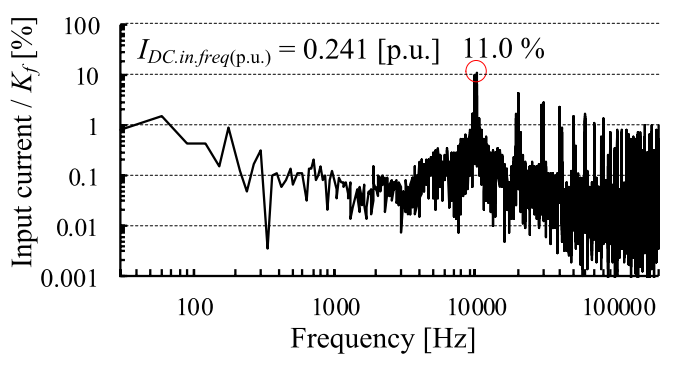

(b) Proposed DPWM.

Fig. 19. Harmonic components of DC-link current at $m=0.705, \cos \varphi=0.819$ (under same conditions as in Figs. 10-11) with consideration for frequency dependency of ESR in electrolytic capacitors

by:

$$
\begin{aligned}
& L_{n_{-} \text {Conv.DPWM }}=L_{o} \cdot F_{I}=L_{o} \cdot 1=5000 \mathrm{~h} \\
& L_{n_{-} \text {Prop.DPWM }}=L_{o} \cdot F_{I}=L_{o} \cdot 1.26=6300 \mathrm{~h}
\end{aligned} .
$$

where $L_{o}$ is 5000 hours in case of RWF series, Nippon Chemi-Con Corp. The ripple current factor $F_{I}$ is calculated by using the results in Fig. 19 based on the technical notes on electrolytic capacitors ${ }^{(13)}$.

Note that the above lifetime estimation is just one example. However, it can be concluded that the application of the proposed DPWM might extend the lifetime of the electrolytic capacitor about 1.26 times longer than that with the conventional DPWM.

\section{Conclusion}

A novel DPWM was proposed to reduce the DC-link current harmonics of the three-phase VSI, which flowed through the DC-link capacitor, over the wide variation of the load power factor. This modulation method contributed the long lifetime of the smoothing capacitor in the motor drive system. Furthermore, this strategy required only one carrier; thus, high cost hardware such as FPGA was unnecessary. The DC-link current harmonics were reduced by shifting two unclamped modulating signals in every half control period. In addition, the injection of the zero sequence signal to all discontinuous modulating signals optimized the phase of clamped modulating signal and its clamped value according to the conditions of the output phase currents; consequently, 
the DC-link current harmonics were reduced even when the load power factor varied.

The experimental results confirmed that the application of the proposed DPWM reduced the RMS value of the DC-link current by $18.3 \%$ with the consideration for the frequency dependency of the ESR of the electrolytic capacitor. The lifetime estimation results confirmed that the DC-link RMS current reduction of $18.3 \%$ could lead to the lifetime extension of 1.26 times for the electrolytic capacitor. Furthermore, the application of the proposed DPWM reduced the DC-link current harmonics over entire range of the load power factor, i.e. in both driving mode and regenerative braking mode.

\section{References}

( 1 ) M. Fleischer and K. Kondo: "Reduced Model Identification and Parameter Estimation for Traction Drive-Trains", IEEJ J. Ind. Appl., Vol.4, No.4, pp.486-495 (2015)

( 2 ) K. Tobari and Y. Iwaji: "Quick-Response Technique for Simplified Position Sensorless Vector Control in Permanent Magnet Synchronous Motors", IEEJ J. Ind. Appl., Vol.4, No.5, pp.582-588 (2015)

( 3 ) T. Nagano and J. Itoh: "Parallel Connected Multiple Motor Drive System Using Small Auxiliary Inverter for Permanent Magnet Synchronous Motors", IEEJ J. Ind. Appl., Vol.4, No.1, pp.40-48 (2014)

( 4 ) K. Sun, Q. Wei, L. Huang, and K. Matsuse: "An Overmodulation Method for PWM-Inverter-Fed IPMSM Drive With Single Current Sensor”, IEEE Trans. Ind. Electron., Vol.57, No.10, pp.3395-3404 (2010)

( 5 ) T. Yamaguchi, Y. Tadano, and N. Hoshi: "Using a Periodic Disturbance Observer for a Motor Drive to Compensate Current Measurement Errors", IEEJ J. Ind. Appl., Vol.4, No.4, pp.323-330 (2015)

( 6 ) R. Saitoh, Y. Makaino, and T. Ohnuma: "Adaptive Signal Injection Method Combined with EEMF based Position Sensorless Control of IPMSM Drives", IEEJ J. Ind. Appl., Vol.4, No.4, pp.454-459 (2015)

( 7 ) K. Ueda, S. Morimoto, Y. Inoue, and M. Sanada: "A Novel Control Method in Flux weakening Region for Efficient Operation of Interior Permanent Magnet Synchronous Motor", IEEJ J. Ind. Appl., Vol.4, No.5, pp.619-625 (2015)

( 8 ) J. Hobraiche, J.-P. Vilain, P. Macret, and N. Patin: "A New PWM Strategy to Reduce the Inverter Input Current Ripples", IEEE Trans. Power Electron., Vol.24, No.1, pp.172-180 (2009)

( 9 ) T.D. Nguyen, N. Patin, and G. Friedrich: "Extended Double Carrier PWM Strategy Dedicated to RMS Current Reduction in DC Link Capacitors of Three-Phase Inverters", IEEE Trans. Power Electron., Vol.29, No.1, pp.396406 (2014)

(10) E. Ün and A.M. Hava: "A Near State PWM Method With Reduced Switching Frequency And Reduced Common Mode Voltage For Three-Phase Voltage Source Inverters", in Proc. IEEE International Electric Machines \& Drives Conf., pp.235-240 (2007)

(11) U.-M. Choi, I. Vernica, and F. Blaabjerg: "Effect of asymmetric layout of IGBT modules on reliability of power inverters in motor drive system", in Conf. Proc. 2018 IEEE Aplied Power Electron. Conf. and Expo. (APEC), pp.193-197 (2018)

(12) U.-M. Choi, I. Vernica, and F. Blaabjerg: "Asymmetric Pulse Width Modulation for Improving the Reliability of Motor Drive Inverters", in Conf. Proc. IEEE Energy Convers. Congr. Expo., pp.6430-6435 (2018)

(13) Nichicon Corp., Tokyo, Japan. Technical Notes on Aluminum Electrolytic Capacitors, Cat. 8101E-1. [Online]. Available: http://www.nichiconus.com/english/products/pdf/aluminum.pdf

(14) M. Hinkkanen and J. Luomi: "Induction Motor Drives Equipped With Diode Rectifier and Small DC-Link Capacitance", IEEE Trans. Ind. Appl., Vol.55, No.1, pp.312-320 (2008)

(15) K. Nishizawa, J. Itoh, A. Odaka, A. Toba, and H. Umida: "Current Harmonic Reduction Based on Space Vector PWM for DC-Link Capacitors in ThreePhase VSIs Operating Over a Wide Range of Power Factor", IEEE Trans. Power Electron., Vol.34, No.5, pp.4853-4867 (2019)

(16) M.H. Bierhoff and F.W. Fuchs: "DC-Link Harmonics of ThreePhase Voltage-Source Converters Influenced by the Pulsewidth-Modulation Strategy-An Analysis", IEEE Trans. Ind. Appl., Vol.55, No.5, pp.2085-2092 (2008)

(17) B.P. McGrath and D.G. Holmes: "A General Analytical Method for Calculating Inverter DC-Link Current Harmonics”, IEEE Trans. Ind. Appl., Vol.45, No.5, pp.1851-1859 (2009)

(18) T. Takeshita: "Output Voltage Harmonics Suppression of Matrix Converters Using Instantaneous Effective Values", in Conf. Proc. IEEE Energy Convers. Congr. Expo., 270_0839 (2010)

(19) K. Nishizawa, J. Itoh, A. Odaka, A. Toba, and H. Umida: "Reduction of DClink current harmonics for Three-phase VSI over Wide Power Factor Range using Single-Carrier-Comparison Discontinuous PWM", in Conf. Proc. European Conf. on Power Electron., No.0297 (2017)

(20) A.M. Hava, R.J. Kerkman, and T.A. Lipo: "Simple Analytical and Graphical Methods for Carrier-Based PWM-VSI Drives", IEEE Trans. Power Electron., Vol.14, No.1, pp.49-61 (1999)

(21) J.M. Erdman, R.J. Kerkman, D.W. Schelegel, and G.L. Skibinski: "Effect of PWM inverters on AC Motor Bearing Currents and Shaft Voltages", IEEE Trans. Ind. Appl., Vol.32, No.2, pp.250-259 (1996)

(22) E. Zhong and T.A. Lipo: "Improvements in EMC Performance of Inverter Fed Motor Drives", IEEE Trans. Ind. Appl., Vol.31, No.6, pp.1247-1256 (1995)

(23) Nippon-Chemi-Con Corp, Tokyo, Japan. Datasheet of Aluminum Electrolytic Capacitor (RWF Series), Cat. E1001K. [Online]. Available: http://www. chemicon.com/upload/files/7/1/20632816534d9b1b1cc5c87.pdf

Koroku Nishizawa (Student Member) received the B.S. degree in

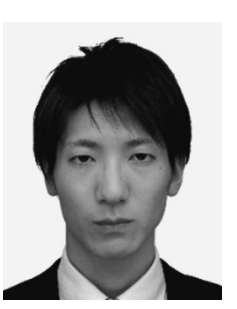
electrical, electronics and information engineering from Nagaoka University of Technology, Niigata, Japan, in 2015, where he is currently working toward the Ph.D. degree. He is a student member of IEEJ and IEEE. His current research focuses on the modulation strategy of converters.

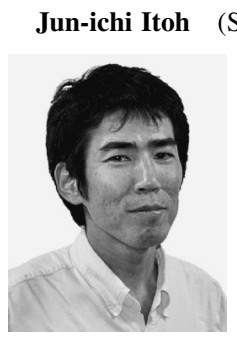

(Senior Member) received the M.S. and Ph.D. degrees in electrical and electronic systems engineering from Nagaoka University of Technology, Niigata, Japan in 1996, 2000, respectively. From 1996 to 2004, he was with Fuji Electric Corporate Research and Development Ltd., Tokyo, Japan. He was with Nagaoka University of Technology, Niigata, Japan as an associate professor. Since 2017 , he has been a professor. His research interests are matrix converters, $\mathrm{dc} / \mathrm{dc}$ converters, power factor correction techniques, energy storage system and adjustable speed drive systems. He received IEEJ Academic Promotion Award (IEEJ Technical Development Award) in 2007. In addition, he also received Isao Takahashi Power Electronics Award in IPEC-Sapporo 2010 from IEEJ, 58th OHM Technology Award from The Foundation for Electrical Science and Engineering, November, 2011, Intelligent Cosmos Award from Intelligent Cosmos Foundation for the Promotion of Science, May, 2012, and Third prize award from Energy Conversion Congress and Exposition-Asia, June, 2013. Prizes for Science and Technology (Development Category) from the Commendation for Science and Technology by the Minister of Education, Culture, Sports, Science and Technology, April 2017. He is a senior member of the Institute of Electrical Engineers of Japan, the Society of Automotive Engineers of Japan and the IEEE.

Akihiro Odaka

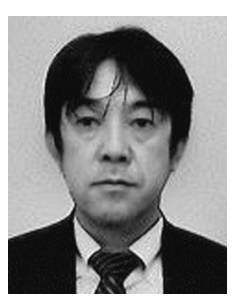

(Member) received the B.S. and M.S. degrees from Tokyo Denki University, Tokyo, Japan, in 1996 and 1998, respectively. Since 1998, he has been with Fuji Electric Co., Ltd., Tokyo. He is a member of IEEJ and IEEE. His research interests include static converters and power semiconductor applications. 
Akio Toba (Senior Member) received the M.E. and Ph.D. degrees

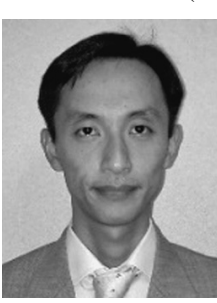
from Tokyo Metropolitan University, Tokyo, Japan, in 1994 and 2006, respectively. In 1994, he joined Fuji Electric Co. Ltd., Tokyo, where he has been conducting the research and development of power electronics, motor drives, and electric machines. From 1997 to 1999, he was a Visiting Researcher with Wisconsin Electric Machines and Power Electronics Consortium, University of Wisconsin, Madison, USA. He is a senior member of IEEJ and a member of IEEE.
Hidetoshi Umida (Fellow) received the B.E., M.E. and Ph.D. degrees in electrical engineering from Tokyo Institute of Technology, Tokyo, Japan, in 1970, 1981 and 1984, respectively. Since 1984, he has been with Fuji Electric Co., Ltd., Tokyo. He is currently a Chief Engineer with Fuji's Corporate R\&D Headquarters. His research interests include control theory and its application to motor drives and converters. He is a fellow of IEEJ and a member of IEEE. 